\title{
Androgen Regulation of Dendritic Growth and Retraction in the Development of a Sexually Dimorphic Spinal Nucleus
}

\author{
Linda A. Goldstein, Elizabeth M. Kurz, and Dale R. Sengelaub \\ Program in Neural Science and Department of Psychology, Indiana University, Bloomington, Indiana 47405
}

\begin{abstract}
The spinal nucleus of the bulbocavernosus (SNB) is a sexually dimorphic group of motoneurons whose development and maintenance are under androgenic control. Exposure to androgens early in development permanently alters SNB motoneuron number and soma size; in adulthood, androgens regulate dendritic and synaptic architecture. The present set of experiments investigates the influence of androgens on the development of SNB dendritic morphology.

In normal males, SNB dendritic growth is biphasic, reaching exuberant lengths by the fourth postnatal week and then retracting to adult lengths by 7 weeks of age. This dendritic growth is androgen dependent-males castrated on postnatal day $(P) 7$ and given daily injections of testosterone propionate (TP) had exuberant dendritic lengths similar to those of normal males; dendritic length in oil-treated males remained at P7 levels. The early exuberant dendritic length was retained in TP-treated males through P49.

The retraction of SNB dendrites after P28 is also influenced by androgens. Males castrated at P28 and given testosterone implants retained exuberant dendritic length at P49; blank-implanted males had significantly shorter dendritlc lengths by P70. These results suggest that androgens are necessary for the early exuberant growth of SNB dendrites. Furthermore, the subsequent retraction of SNB dendrites may be halted when testosterone titers reach a critical level during puberty, stabilizing their adult length.
\end{abstract}

Steroid hormones produce major sex differences in the nervous system by acting during critical periods to regulate fundamental processes of development (Goy and McEwen, 1980; MacLusky and Naftolin, 1981; Arnold et al., 1987). The use of discrete model neural systems has made possible an understanding of the role of steroid hormones in regulating neuron number, morphology, and connectivity (Arnold and Gorski, 1984; Kelley, 1986). One such model system is the spinal nucleus of the bulbocavernosus (SNB), a sexually dimorphic cluster of motoneurons in the lumbar region of the rat spinal cord. In males, SNB motoneurons innervate the perineal muscles bulbocavernosus (BC) and the levator ani (LA; Breedlove and Arnold, 1980; Schroder, 1980; Ueyama et al., 1987), as well as the anal sphincter (McKenna and Nadelhaft, 1986). The BC and LA muscles attach exclusively to the penis and control male copulatory re-

\footnotetext{
Received June 8, 1989; revised Aug. 14, 1989; accepted Sept. 19, 1989.

We wish to thank Anne Cover for her excellent technical assistance, Heather Karcher Godfrey for assistance with data analysis, and Caitlin Anne Sengelaub for her contribution. This work was supported by NIH grant NS 24588 to D.R.S.

Correspondence should be addressed to Dale R. Sengelaub at the above address.

Copyright (C) 1990 Society for Neuroscience $0270-6474 / 90 / 030935-12 \$ 02.00 / 0$
}

flexes. For example, the $\mathrm{BC}$ muscle contracts during penile erection, particularly erection that includes flaring or cupping of the glans (Sachs, 1982; Hart and Melese-D'Hospital, 1983). Adult females, which lack the $\mathrm{BC} / \mathrm{LA}$ musculature, have only a small number of SNB motoneurons which innervate the nondimorphic anal sphincter (Cihak et al., 1970; McKenna and Nadelhaft, 1986).

The number, morphology, and connectivity of SNB motoneurons, as well as the presence of the perineal target musculature, are regulated by the action of androgens during a critical period of development. At birth, males and females possess both large numbers of SNB motoneurons and the perineal musculature. However, in females the musculature atrophies early postnatally (Cihak et al., 1970), and their SNB motoneuron number is reduced through a normally occurring motoneuron death which is significantly greater than that seen in males (Nordeen et al., 1985; Sengelaub and Arnold, 1986). Females treated perinatally with the androgen testosterone propionate (TP) have a significantly reduced motoneuron death (Nordeen et al., 1985) and retain the BC/LA muscles (Cihak et al., 1970; Breedlove and Arnold, 1983b). These TP-treated females also have larger SNB motoneurons than normal females (Breedlove et al., 1982; Breedlove and Arnold, 1983b; Lee et al., 1989). Conversely, males treated with antiandrogens or which are androgen insensitive as a consequence of the genetic testicular feminization mutation (Tfm) develop a feminine SNB (Breedlove and Arnold, 1981, 1983a; Sengelaub et al., 1989a). The number of SNB motoneurons in females treated with either estrogen or dihydrotestosterone, the primary active metabolites of testosteronc, rcmains feminine (Brecdlove et al., 1982; Breedlove and Arnold, 1983b; Sengelaub et al., 1989b), whereas treatment with both of these metabolites combined produces masculine SNB motoneuron numbers (Goldstein and Sengelaub, 1989). Androgens are also involved in regulating neuromuscular synapse elimination in the SNB system. Postnatal castration hastens the elimination of multiple inputs to LA muscle fibers, and castration followed by androgen replacement results in the retention of multiple innervation in this muscle (Jordan et al., 1989a, b; Lubischer et al., 1989).

In adulthood, both SNB motoneurons (Breedlove and Arnold, $1980,1983 \mathrm{c}$ ) and their target muscles (Dube et al., 1976) accumulate androgens and remain sensitive to androgenic effects. Changes in androgen levels produced with castration and androgen treatment result in significant and reversible alterations in SNB soma size and dendritic length (Breedlove and Arnold, 1981; Kurz et al., 1986a; Forger and Breedlove, 1987), synaptic organization (Matsumoto et al., 1988a, b), and muscle mass (Wainman and Shipounoff, 1941; Forger and Breedlove, 1987).

Dendritic development has been described for a number of 
neuronal types. Ramón y Cajal (1909-1911) was the first to note changes in dendrites during development. He distinguished an initial phase of outgrowth followed by a phase of regulation and resorption of dendrites. This pattern of an initial exuberant growth followed by a retraction and modification has subsequently been found in many different developing neurons: Purkinje cells (Weiss and Pysh, 1978), interneurons of the substantia gelatinosa (Falls and Gobel, 1979), nucleus laminaris (Smith, 1981), retinal ganglion cells (Morest, 1969b; Maslim et al., 1986; Ramoa et al., 1987; Dann et al., 1988), and somatosensory cortex (Greenough and Chang, 1988). In contrast, dendritic development in other developing neurons is reported to be monotonic, and the dendritic arbors of these cells simply increase to their adult lengths (e.g., Voyvodic, 1987; Petit et al., 1988; Lasiter et al., 1989).

Studies using radioimmunoassay or gas-liquid chromatography techniques from a variety of laboratories have consistently demonstrated that during postnatal development, and especially with the onset of puberty, the amount of circulating testosterone in male rats changes dramatically. Plasma testosterone levels are reported to decline perinatally and remain low during the first 4 postnatal weeks of life (Ketelslegers et al., 1978; Corpechot et al., 1981). With the onset of puberty, testosterone titers begin to rise gradually after the fourth postnatal week (Resko et al., 1968; Moger, 1977; Ketelslegers et al., 1978; Corpechot et al., 1981). By 7 weeks of age, testosterone titers are approximately half of adult values (Resko et al., 1968; Moger, 1977; Corpechot et al., 1981), and masculine sexual behavior ensues with the first occurrence of mounts, intromissions, penile flips and flares, and ejaculations (Sodersten et al., 1977; Sachs and Meisel, 1979; Meaney and Stewart, 1981). After this time, testosterone titers continue to rise, reaching their adult levels a few weeks later (Resko et al., 1968; Ketelslegers et al., 1978; Corpechot et al,, 1981).

Given the substantial influence androgens exert on developing and mature SNB motoneurons, we examined whether the development of SNB dendritic morphology was also susceptible to hormonal influence. In Experiment I we investigate the normal pattern of dendritic growth in the SNB through puberty and into adulthood. To determine if androgens are involved in SNB dendritic development, in Experiments II and III we examine dendritic growth of SNB motoneurons under hormonally altered conditions.

\section{Materials and Methods}

\section{Animals}

Experiment I: normal development. To study the normal development of SNB dendritic morphology, male rats (Sprague-Dawley) were obtained starting at postnatal day $(\mathrm{P}) 7(\mathrm{Pl}=$ day of birth). $\mathrm{P} 7$ was chosen as the youngest age examined because by this time cell death in the SNB is virtually complete (Nordeen et al., 1985), and dendritic development would therefore not be confounded by changes in motoneuron number induced by hormonal manipulation (see below). Dendritic morphology was examined at 3 week intervals thereafter (P28, P49, and P70) in order to assess dendritic development through puberty into adulthood. All males were obtained from litters bred in our colony (breeding males and females were obtained from Harlan Laboratories), and litters were culled to 8 pups when necessary, retaining males preferentially. The animals were maintained on a 14:10 light: dark cycle with ad lib access to food and water. Four males were used at each age (total $n=16$ ).

Experiment II: early castration. To determine if androgens were required for early postnatal dendritic growth, males were castrated at P7 under ether anesthesia. Following gonadectomy, males were given daily subcutaneous injections of $0.1 \mathrm{mg}$ TP (Steraloids) dissolved in sesame oil or an equal volume $(0.05 \mathrm{ml})$ of vehicle alone. This dosage of TP results in significantly higher plasma testosterone titers than would normally be present in males at these ages (Resko et al., 1968; Moger, 1977; Smith et al., 1978; Corpechot et al., 1981). Another group of castrated males received dosages of TP that were adjusted for increments in body weight $(0.1 \mathrm{mg} / 50 \mathrm{gm}$ body weight; Jordan et al., 1989a, b). These 2 treatment regimes produced identical measures of SNB dendritic length and soma size, and the groups were therefore collapsed in subsequent analyses. The morphology of SNB motoneurons was assessed at either P28 or P49 for both the hormone- and oil-treated castrates (4-6 males/ group; total $n=19$ ).

Experiment III: late castration. To determine if androgens were involved in late postnatal dendritic development, male rats were castrated on P28. These males were implanted with Silastic capsules $(3.18 \mathrm{~mm}$ outer diameter; $1.57 \mathrm{~mm}$ inner diameter; $45 \mathrm{~mm}$ long) that either containcd testostcrone ( $T$; Steraloids) or were left blank. $\Lambda$ gain, this length of hormone-filled Silastic results in significantly higher plasma $T$ titers than would normally be present in males at these ages, producing plasma $T$ levels in the normal adult range (Smith et al., 1978; Corpechot et al., 1981). The morphology of SNB motoneurons was assessed at either P49 or P70 for both the hormone- and blank-implanted castrates (4 males/group; total $n=16$ ).

\section{Histochemistry}

Because we were interested in the fine morphological detail of SNB motoneurons and their dendritic arbors, we used cholera toxin conjugated to HRP (CTHRP, List Biological). This conjugatc has becn demonstrated to be extremely sensitive for the visualization of the dendritic arbors of retrogradely labeled SNB motoneurons (Kurz et al., 1986a, 1989a; Forger and Breedlove, 1987). For CTHRP injection, animals were anesthetized with ether and the perineal muscles exposed. Unilateral injections of CTHRP $(0.3-0.5 \mu \mathrm{l}$ of a $0.2 \%$ solution) were made into the left BC. Animals were allowed a $48 \mathrm{hr}$ survival time, a period which has been demonstrated to be optimal for HRP labeling of the SNB and its processes (Kurz et al., 1986a). All animals were then deeply anesthetized with an overdose of urethane and perfused intracardially with saline followed by cold $1 \%$ paraformaldehyde $/ 1.25 \%$ glutaraldehyde. Lumbar spinal cords were removed, postfixed briefly, embedded in gelatin, and frozen-sectioned transversely at $40 \mu \mathrm{m}$ into alternate series. The tissue was then reacted immediately using a modified tetramethyl benzidine protocol (Mcsulam, 1978), and sections were counterstained with thionin.

\section{Morphometry}

The numbers and distributions of CTHRP-filled motoneurons were assessed in a series of sections $160 \mu \mathrm{m}$ apart through the entire extent of the SNB. Counts of labeled motoneurons in the SNB were made in these sections under bright-field illumination, where somas and nuclei could be visualized and cytoplasmic inclusion of CTHRP reaction product confirmed. Under dark-field illumination, all CTHRP-labeled dendritic processes were drawn at a final magnification of $250 \times$, and their length was measured with a camera lucida and a computer-based imageanalysis system. In order to estimate the amount of dendritic arbor per motoneuron, all dendritic lengths for an animal were summed and then divided by the number of CTHRP-labeled somas encountered in the same sections. This index of dendritic length per motoneuron has been shown to be a sensitive indicator of changes in dendritic morphology after castration and hormone replacement in adults (Kurz et al., 1986a) and has also revealed both normal and hormonally induced morphological differences between motoneuron nuclei (Kurz et al., 1986b, 1987, 1989a).

The soma size of SNB motoneurons was determined under brightfield illumination by measuring the cross-sectional area of all CTHRPfilled motoneurons encountered in the same set of sections used for dendritic analysis (final magnification, $400 \times ; n=11-31$ motoneurons/ animal).

Statistical analysis consisted of analyses of variance and appropriate planned comparisons as described below.

\section{Results}

Normal dendritic and somal development

Injections of CTHRP into the BC successfully labeled ipsilateral SNB motoneurons at all ages. The quality of CTHRP labeling 


\section{Normal}

P7

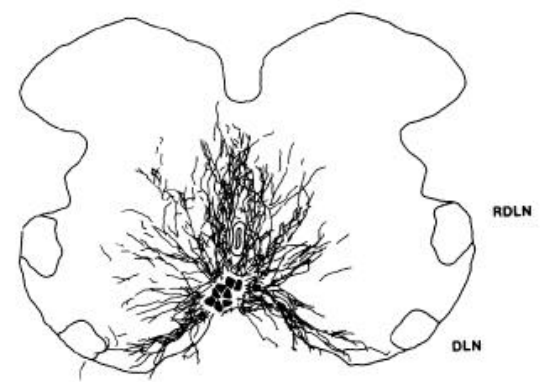

\section{Normal}

P28
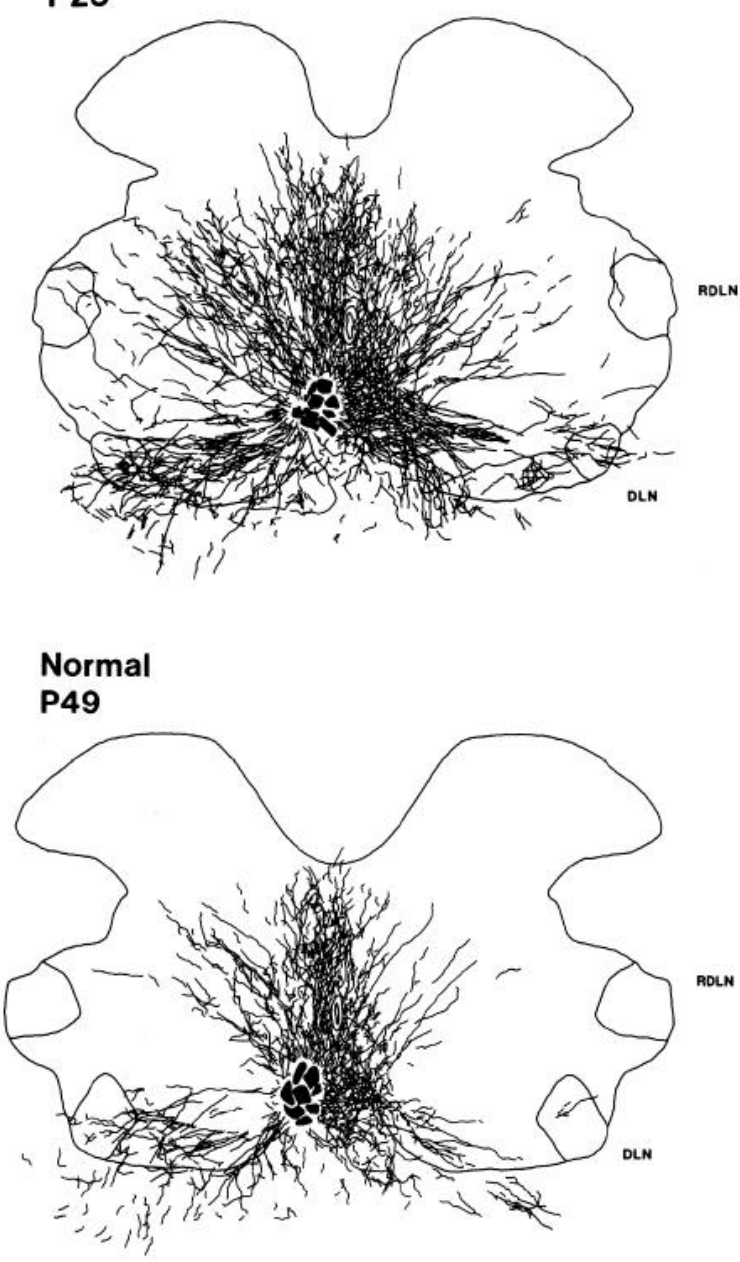
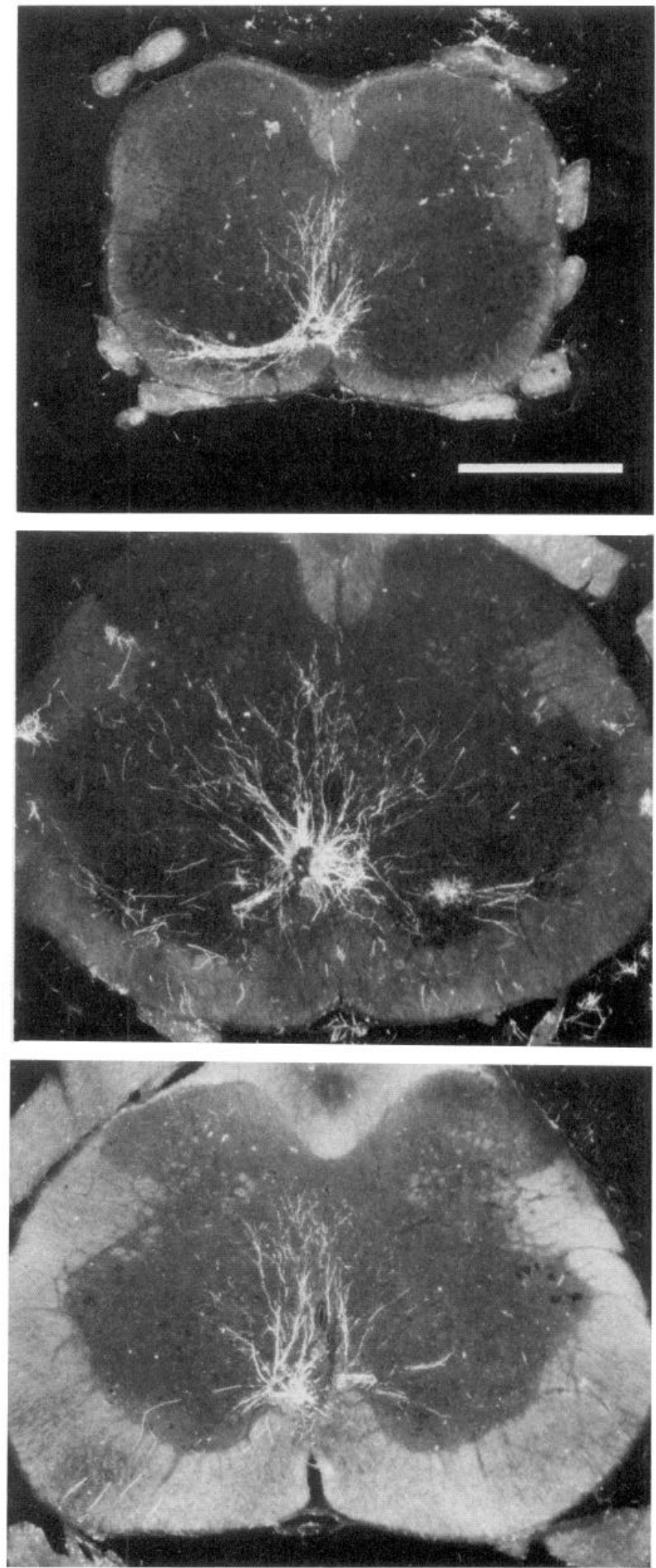

Figure 1. Left, Camera lucida composite drawings of CTHRP-labeled processes drawn at $320 \mu \mathrm{m}$ intervals through the total extent of the SNB. Right, Dark-field photomicrographs of transverse sections through the lumbar spinal cord of a normal male at P7 (upper), at P28 (middle), and P49 (lower) after CTHRP injection into the BC muscle. DLN, dorsolateral nucleus; $R D L N$, retrodorsolateral nucleus. Scale bar, $500 \mu \mathrm{m}$. 

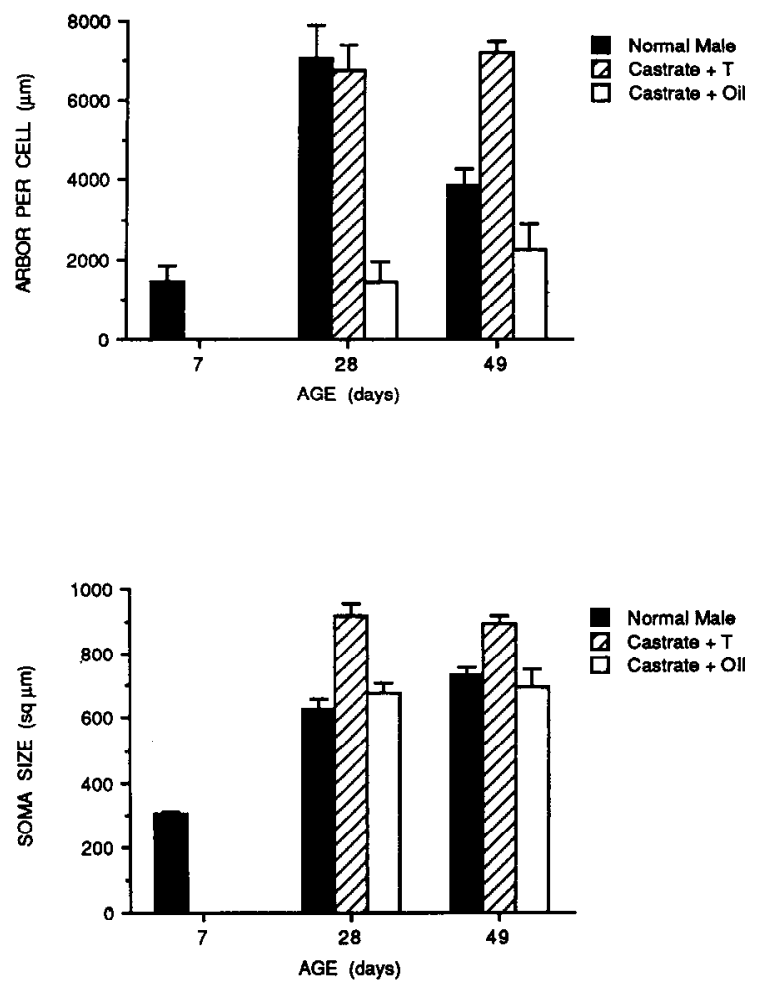

Figure 2. Dendritic length per motoneuron (upper) and soma area (lower) of SNB motoneurons in normal males at P7, P28 and P49 (filled bars), and animals castrated at P7 and treated with TP (striped bars) or oil (open bars) at P28 and P49. Bar heights represent grand means \pm SEM for 4-6 animals in each group.

was consistent over groups (see Fig. 1) and comparable to that obtained in previous studies (Kurz et al., 1986a, b, 1987). The distribution of CTHRP-labeled dendrites was similar to that previously reported. Labeled dendritic processes extended bilaterally to the lateral edges of the gray matter, densely to the dorsal funiculi, as well as into the area of the contralateral SNB at all ages examined (Kurz et al., 1986a).

The development of dendritic length in SNB motoneurons was found to occur in 2 phases: a period of exuberant growth between P7 and P28, followed by a period of retraction to adult dendritic lengths by P49 (see Figs. 1, 2). At P7 the average dendritic length per SNB motoneuron was $1463.2 \mu \mathrm{m}( \pm 384.2$ SEM), which was significantly less than that of normal adults $[\mathrm{P} 70 x=4113.7 \mu \mathrm{m} \pm 309.4 \mathrm{SEM} ; F(1,12)=11.91, p<0.005]$. Between P7 and P28, the dendritic arbors of SNB motoneurons grew exuberantly to almost 5 times their P7 length [P28 $\bar{x}=$ $7034.5 \pm 866.2 \mu \mathrm{m} ; F(1,12)=52.65, p<0.0001]$. This dendritic length at P28 was also significantly above the normal P70 dendritic length per motoneuron $[F(1,12)=14.47, p<0.003]$. Between P28 and P49, dendritic length declined significantly to $3868.6 \pm 430.7 \mu \mathrm{m}[F(1,12)=17.00, p<0.002]$. Following this $45 \%$ decrease, dendritic length remained stable, and both P49 and P70 values were in the normal adult range obtained in other studies (Kurz et al., 1986a).

Soma area between P7 and P70 showed a gradual increase in sice (see Figs. 2, 3). At P7, soma size a veraged $302.1 \mu \mathrm{m}^{2}( \pm 6.2$ SEM), which is approximately $35 \%$ of adult size. Soma area increased significantly between P7 and P28, to a mean of 628.0 $\pm 29.3 \mu \mathrm{m}^{2}[\mathrm{~F}(1,12)=90.57, p<0.0001]$. Significant increases
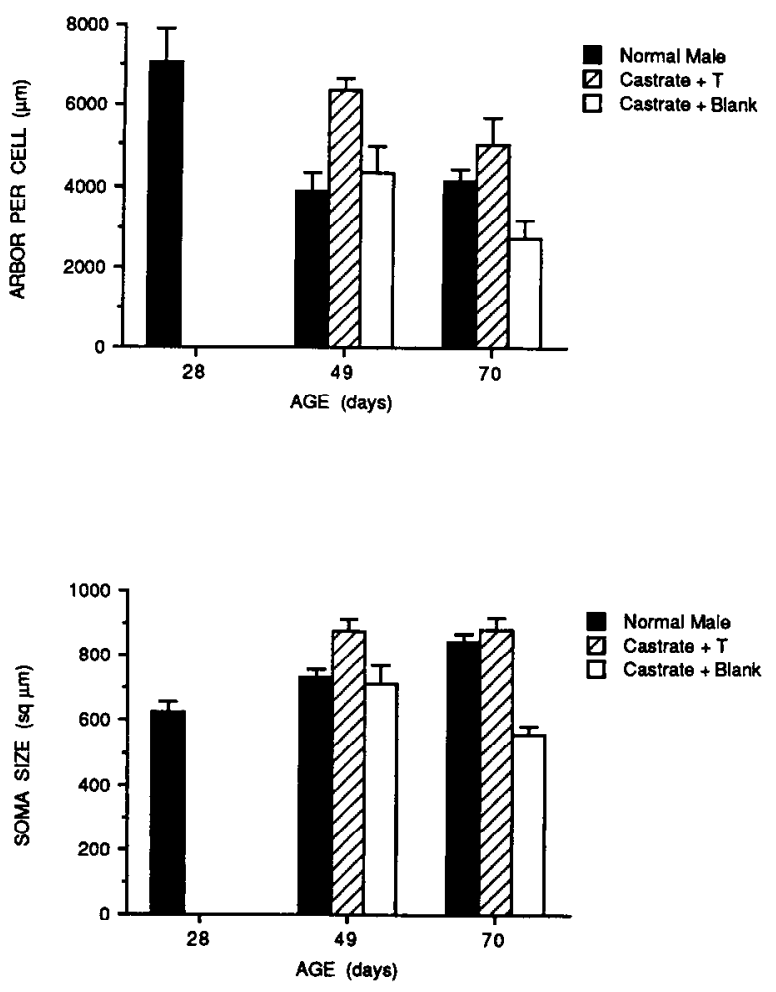

Figure 3. Dendritic length per motoneuron (upper) and soma area (lower) of SNB motoneurons in normal males at P28, P49, and P70 (filled bars), and animals castrated at P28 and implanted with T-filled implants (striped bars) or blank implants (open bars) at P49 and P70. Bar heights represent grand means \pm SEM for 4 animals in each group.

in soma size were also observed between P28 and P49, and between P49 and P70 [P49 $\bar{x}=732.5 \pm 27.3 \mu \mathrm{m}^{2} ; \mathrm{P} 70 \bar{x}=842.6$ $\pm 26.4 \mu \mathrm{m}^{2} ; F \mathrm{~s}(1,12)>9.0 ; p$ 's $\left.<0.007\right]$.

\section{Dendritic and somal development after early castration}

Males castrated at P7 and injected with TP showed the same exuberant growth seen in intact males, demonstrating that our TP treatment regime was sufficient to support normal dendritic development. At P28, dendritic length in TP-treated males did not differ significantly from that of normal males at this age, having an average length of $6818.4 \mu \mathrm{m}( \pm 458.0 \mathrm{SEM})$. However, at P49 dendritic length in TP-treated males was almost twice as long $(\bar{x}=7605.1 \pm 619.0 \mu \mathrm{m})$ as that found in normal males $[\bar{x}=3868.6 \pm 430.7 \mu \mathrm{m} ; F(1,25)=18.04, p<0.001]$.

In contrast, dendritic lengths in oil-treated castrates at P28 and P49 did not differ from their P7 values (see Figs. 2, 4). Oiltreated males at P28 had an average dendritic length of only $1449.1 \pm 521.6 \mu \mathrm{m}$, significantly below that of either normal or TP-treated males $[F$ 's $(1,25)>40, p$ 's $<0.0001]$. At P49, dendritic length in oil-treated males $(\bar{x}=2278.5 \pm 658.7 \mu \mathrm{m})$ was again significantly shorter than that of normal or TP-treated males $\left[F^{\prime} \mathrm{s}(1,25)>5.69, p^{\prime} \mathrm{s}<0.03\right.$; see Figs. 2, 5].

Unlike dendritic growth, soma size after early (P7) castration did not show testosterone dependence. Average soma area in oil-treated males at P28 $\left(x=675.2 \mu \mathrm{m}^{2} \pm 33.1\right.$ SEM) and at P49 $\left(\bar{x}=697.7 \pm 54.2 \mu \mathrm{m}^{2}\right)$ did not differ from that of normal males $\left(\bar{x}=628.0 \pm 29.3 \mu \mathrm{m}^{2}\right.$ and $\bar{x}=732.5 \pm 27.3 \mu \mathrm{m}^{2}$, respectively). However, TP-treated castrates showed significant 

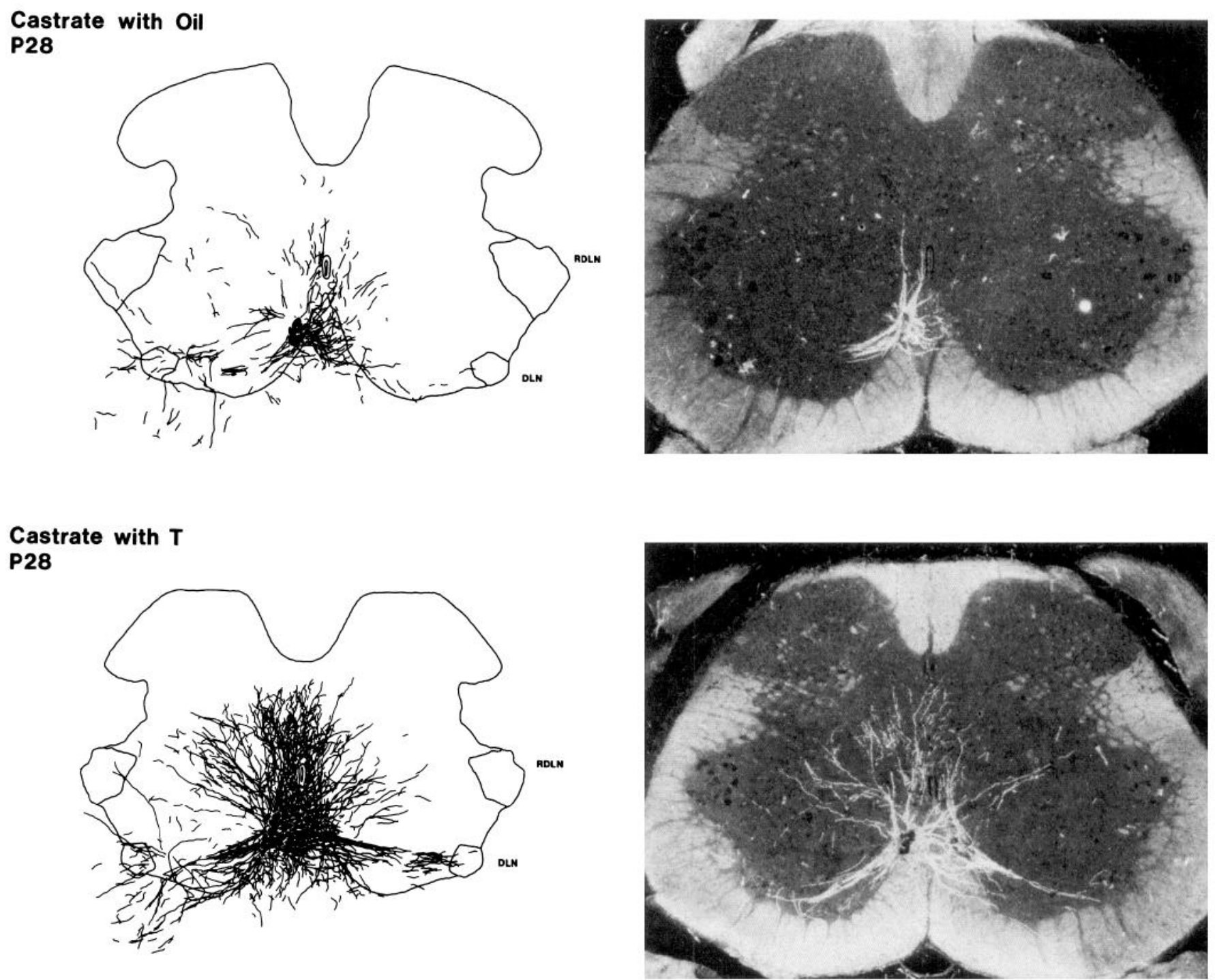

Figure 4. Left, Camera lucida composite drawings of CTHRP-labeled processes drawn at $320 \mu \mathrm{m}$ intervals through the total extent of the SNB. Right, Dark-field photomicrographs of transverse sections through the lumbar spinal cord of a male castrated at P7 and injected with oil (upper) or TP (lower) after CTHRP injection into the BC muscle at P28. Abbreviations and scale as in Figure 1.

increases in soma area relative to normal males at both ages. Soma area of TP-treated males was $46 \%$ larger than that of normal males at $\mathrm{P} 28\left[\bar{x}=918.5 \pm 37.9 \mu \mathrm{m}^{2} ; F(1,24)=38.21\right.$, $p<0.0001]$ and $22 \%$ larger at $\mathrm{P} 49\left[\bar{x}=892.8 \pm 28.2 \mu \mathrm{m}^{2}\right.$; $F(1,24)=10.77, p<0.004$; see Fig. 3]. Because soma size increased in a normal fashion from P7 to P49 in oil-treated castrates, it appears that androgens are not required for normal soma growth during this period. However, in castrates exposed to high levels of TP, soma size was significantly larger than normal at both ages, suggesting a hypermasculinizing effect of early exposure to high $\mathrm{T}$ concentrations (Fig. 3).

\section{Dendritic and somal development after late castration}

Consistent with the results of Experiment II, males castrated at P28 and implanted with T had SNB dendritic lengths at P49 that were longer than those of normal males at this age [64\% longer; $\bar{x}=6353.3 \pm 317.6 \mu \mathrm{m} ; F(1,18)=12.55, p<0.003$ ]. At P70 however, dendritic length in T-implanted castrates $(\bar{x}$
$=5030.7 \pm 665.6 \mu \mathrm{m}$ ) did not differ from that of normal males.

In contrast, dendritic length in blank-implanted castrates at P49 $(\bar{x}=4308.6 \pm 670.9 \mu \mathrm{m})$ did not differ significantly from that of normal males (Figs. 3, 6). At P70, however, dendritic lengths in blank-implanted castrates had declined significantly from $\mathrm{P} 49$ levels $[F(1,18)=5.07, p<0.04]$ and were significantly shorter than that of normal males [castrate + blank $\bar{x}=2728.9$ $\pm 447.8 \mu \mathrm{m} ; F(1,6)=6.48, p<0.03$; Figs. 3, 7].

As was found after early castration, soma size in blank-implanted castrates did not differ from that of normal males at P49 (castrate + blank $\bar{x}=714.8 \pm 54.9 \mu \mathrm{m}^{2}$ ). However, at P70 blank-implanted castrates had significantly smaller soma sizes than those of normal males [castrate + blank $\bar{x}=556.1 \pm 27.6$ $\mu \mathrm{m}^{2} ; F(1,18)=32.14, p<0.0002$; see Fig. 3]. Soma size in $\mathrm{T}$-implanted castrates was significantly larger than that of normal animals at P49 [castrate $+\mathrm{T} \bar{x}=877.8 \pm 34.0 \mu \mathrm{m}^{2} ; F(1,18)$ $=8.32, p<0.01]$. This hypermasculinization was transient, and by P70, soma size in T-implanted castrates was not different from that of normal males (castrate $+\mathrm{T} \bar{x}=882.2 \pm 36.1 \mu \mathrm{m}^{2}$ ). 

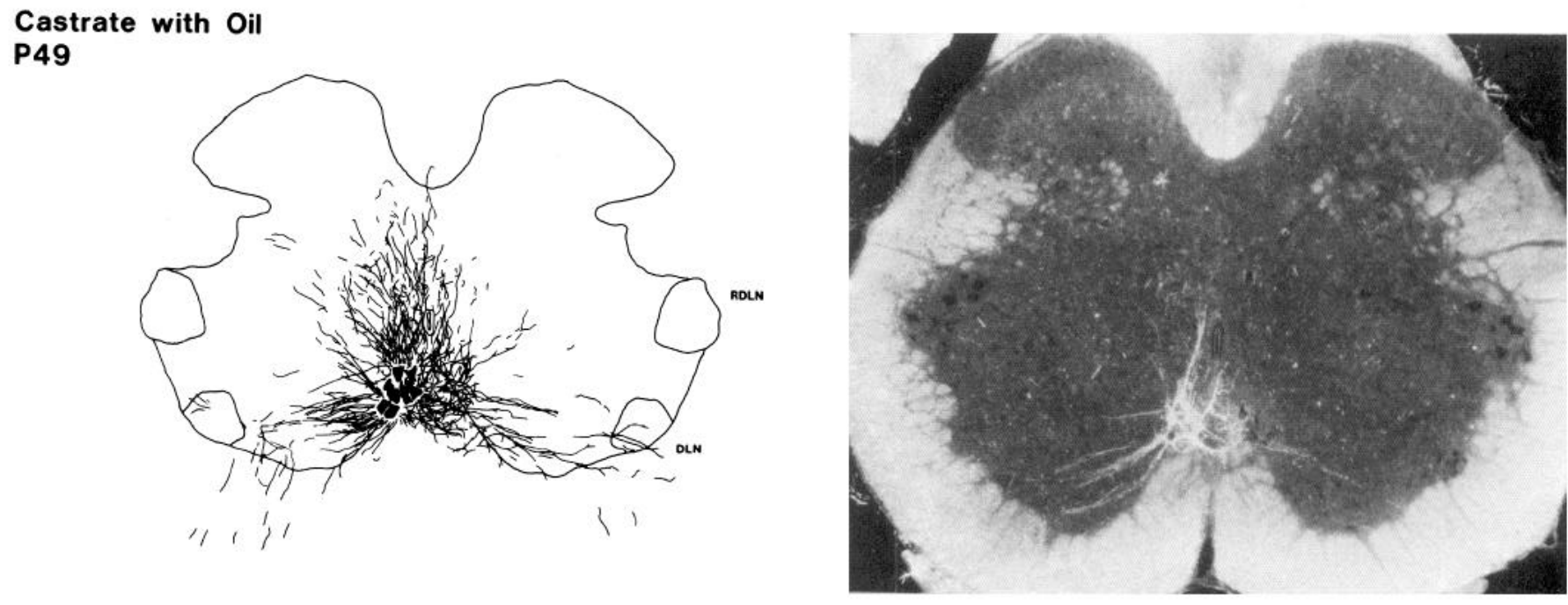

\section{Castrate with T \\ P49}

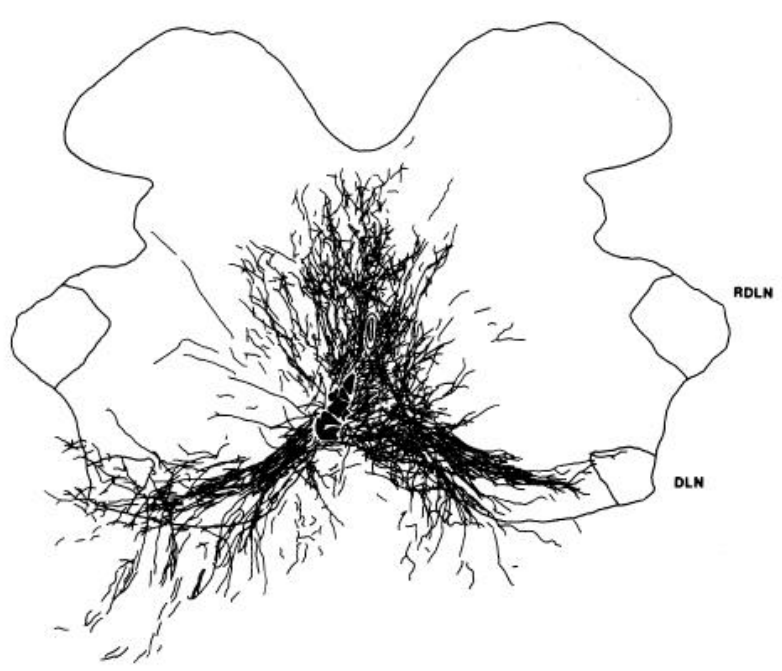

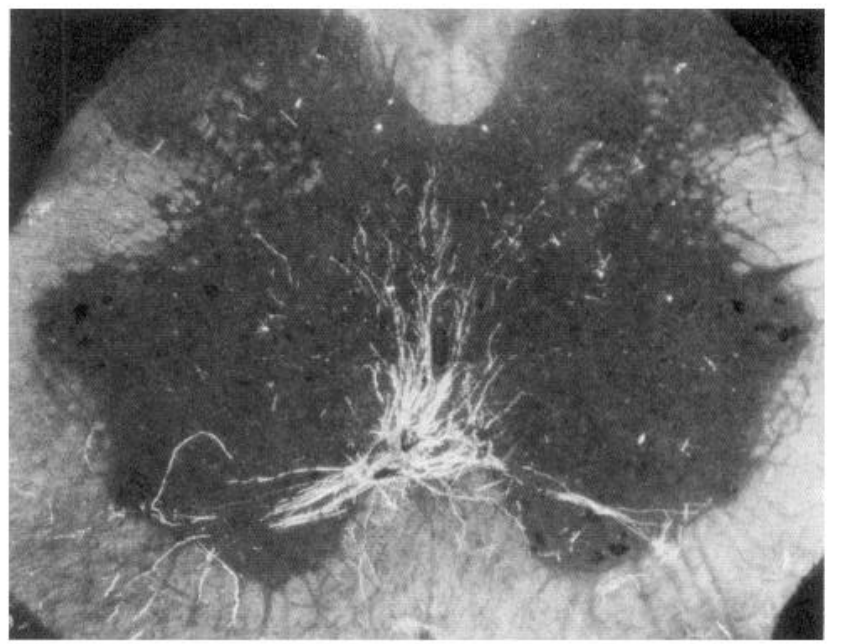

Figure 5. Left, Camera lucida composite drawings of CTHRP-labeled processes drawn at $320 \mu \mathrm{m}$ intervals through the total extent of the SNB. Right, Dark-field photomicrographs of transverse sections through the lumbar spinal cord of a male castrated at P7 and injected with oil (upper) or TP (lower) after CTHRP injection into the BC muscle at P49. Abbreviations and scale as in Figure 1.

\section{Discussion}

\section{Normal dendritic development of SNB motoneurons}

The dendritic morphology of SNB motoneurons changes substantially over development and is characterized by 2 phases: a phase of exuberant growth followed by a phase of retraction to adult lengths. Although the dendritic arbor of SNB motoneurons at P7 is substantial, it is approximately $35 \%$ shorter than that of adults. The general shape and distribution of the arbor strongly resemble those of older animals (see Fig. 1). The arbor extends to the limits of the gray matter laterally and dorsally and is sparse in the lateral aspects of lamina VII. Between P7 and P28 dendrites grow exuberantly, resulting in measures of dendritic length per motoneuron at P28 that are nearly twice those of normal adults.

After P28 there is a period of dendritic retraction, and by P49 dendritic length is in its adult range. While the length of the dendritic arbor per SNB motoneuron decreases over this period, the distribution of CTHRP-labeled dendrites does not appear to change; qualitatively, labeled dendrites continue to be distributed throughout the gray matter. The characteristic features of the SNB dendritic arbor were present at all of the ages we examined, having a bilateral and radial organization with extensive lateral and dorsal projections, and a dense ramification into the area of the contralateral half of the nucleus (see Fig. 1). Given that there is a substantial decrease in total length but no apparent change in the general distribution of the arbor, we think it likely that the reduction in overall length is due to a retraction of dendritic branches, rather than changes in the general topology of the dendritic arbor (see Weiss and Pysh, 1978; Dann et al., 1988; McMullen et al., 1988; Ramoa et al., 1988).

By P49 dendritic length and topology are mature and are indistinguishable from those of significantly older males (Kurz et al., 1986a, 1989a; Beversdorf et al., 1989). Interestingly, although T titers at P49 have been shown to be below those of adult males (Resko et al., 1968; Moger, 1977; Corpechot et al., 


\section{Castrate with Blank P49}
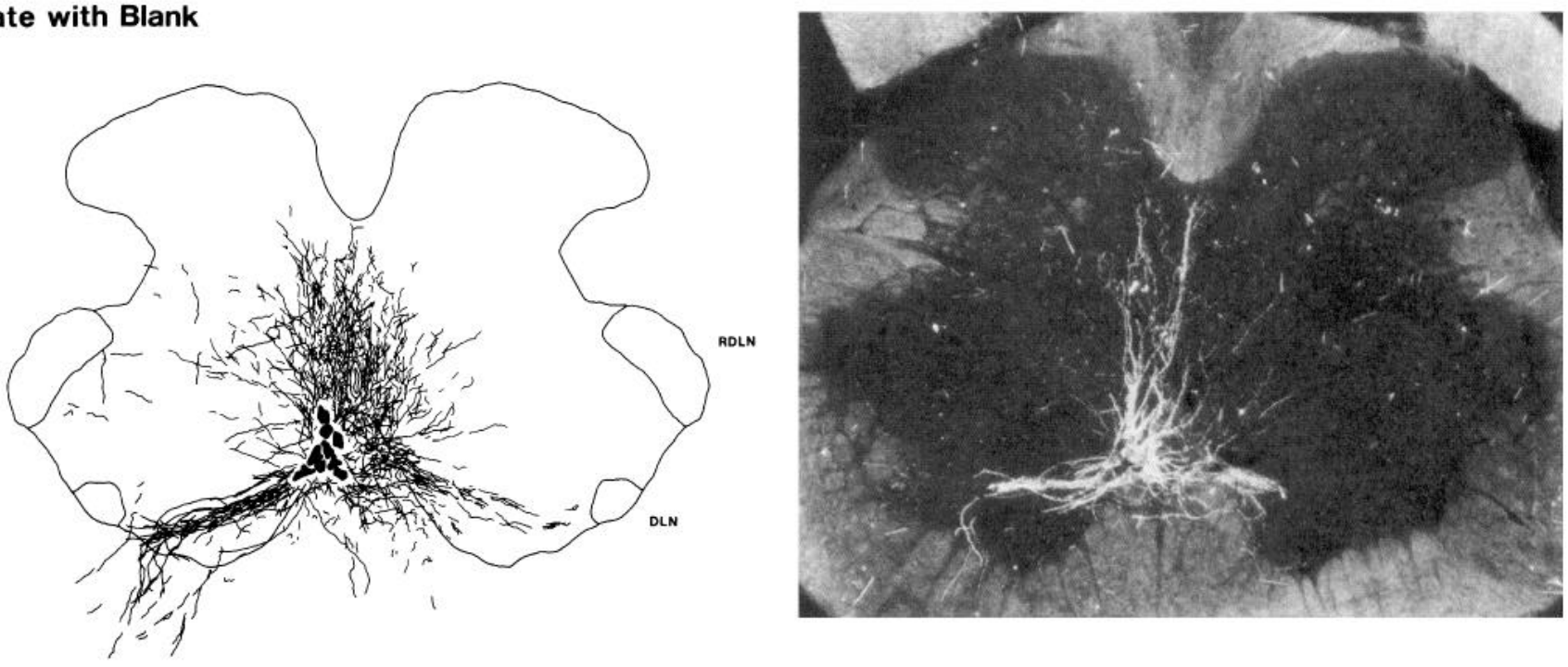

\section{Castrate with T P49}

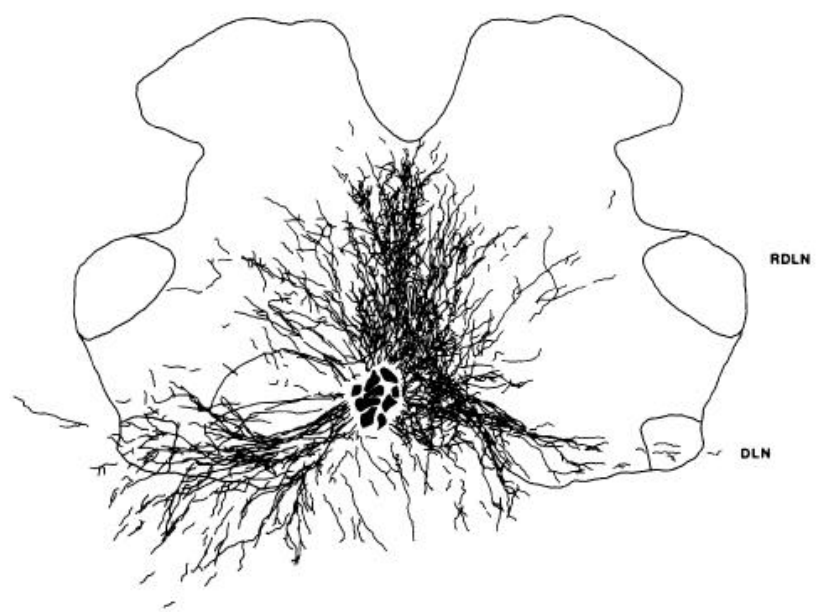

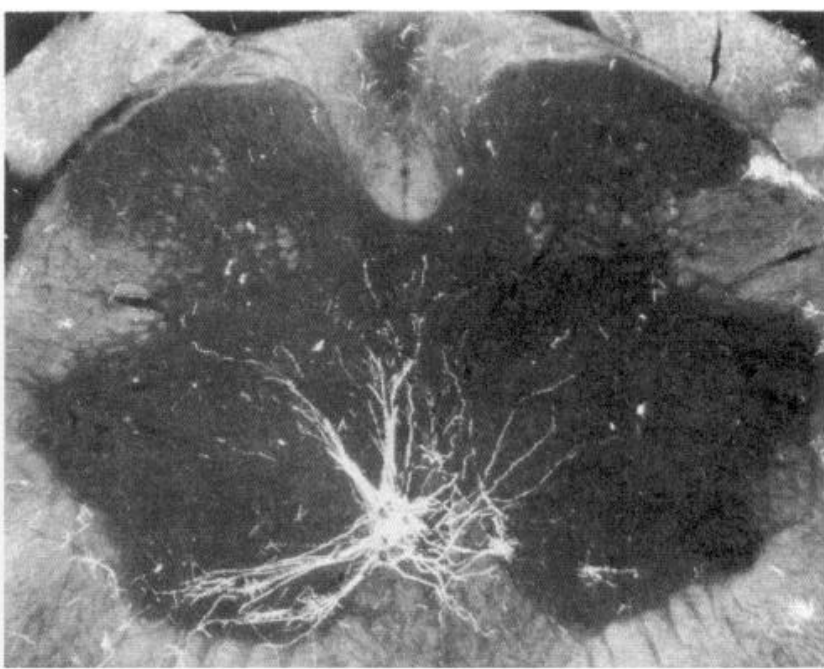

Figure 6. Left, Camera lucida composite drawings of CTHRP-labeled processes drawn at $320 \mu \mathrm{m}$ intervals through the total extent of the SNB. Right, dark-field photomicrographs of transverse sections through the lumbar spinal cord of a male castrated at P28 and implanted with a blank implant (upper) or an implant containing T (lower) after CTHRP injection into the BC muscle at P49. Abbreviations and scale as in Figure 1.

1981), the establishment of mature dendritic morphology at this age is coincident with the onset of sexual functioning of the SNB system. Intromission and ejaculation, 2 copulatory reflexes mediated by SNB motoneurons, first appear at approximately 7 weeks of age (Sodersten et al., 1977; Sachs and Meisel, 1979; Meaney and Stewart, 1981). The onset of these behaviors corresponds closely with the first appearance of erections, penile flips, and flaring of the tip of the erect penis (Sachs and Meisel, 1979), behaviors mediated by the SNB (Sachs, 1982; Hart and Melese-D’Hospital, 1983).

\section{Patterns of dendritic development}

The biphasic pattern of dendritic development (exuberant growth followed by retraction) in the SNB is similar to that seen in several other neural systems (Morest, 1969b; Weiss and Pysh, 1978; Falls and Gobel, 1979; Smith, 1981; Maslim et al., 1986; Ramoa et al., 1987; Dann et al., 1988; Greenough and Chang, 1988). For example, dendritic length in mouse Purkinje cells increases rapidly through postnatal day 20 and then declines significantly through postnatal day 35 (Weiss and Pysh, 1978). This biphasic pattern of changing dendritic length was thought to reflect the rapid proliferation of dendrites followed by the loss of dendritic segments. Similarly, both cat retinal ganglion cells and rabbit neocortical cells display a period of exuberant dendritic branching followed by a decline to adult levels (Ramoa et al., 1987; McMullen et al., 1988).

In contrast, dendritic development in other developing neurons is reported to be monotonic, and the dendritic arbors of these cells simply increase to their adult lengths. For example, dendritic growth in rostral nucleus of the solitary tract of the rat is characterized by a rapid expansion to adult lengths of first and second order dendrites through postnatal day 20 , and in the case of second-order dendrites of multipolar cells, dendritic growth continues through postnatal day 70 (Lasiter et al., 1989). In the neocortex of the rat, pyramidal cells in layer $\mathrm{V}$ continue to increase in dendritic length into adulthood, and this growth 


\section{Castrate with Blank P70}

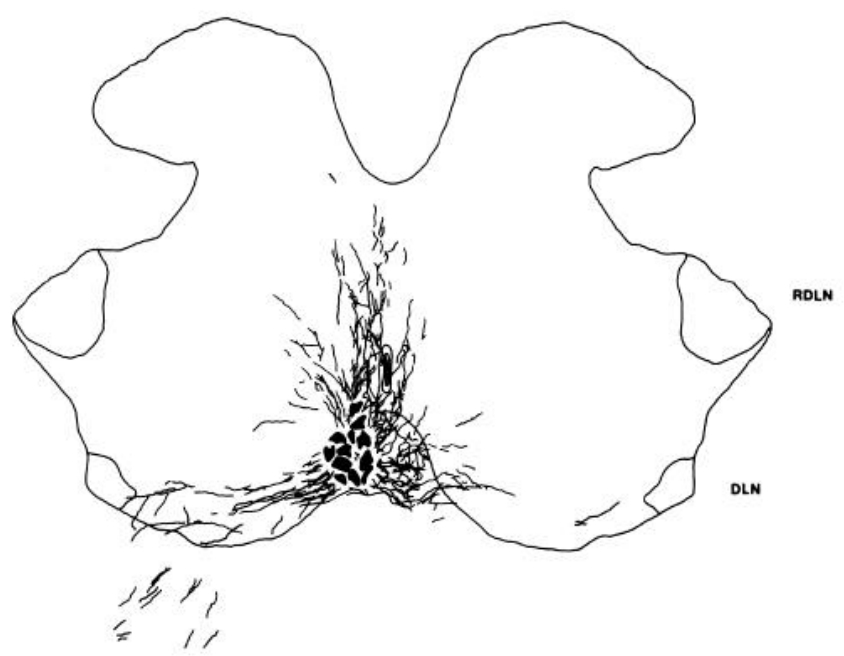

\section{Castrate with $\mathrm{T}$ \\ P70}

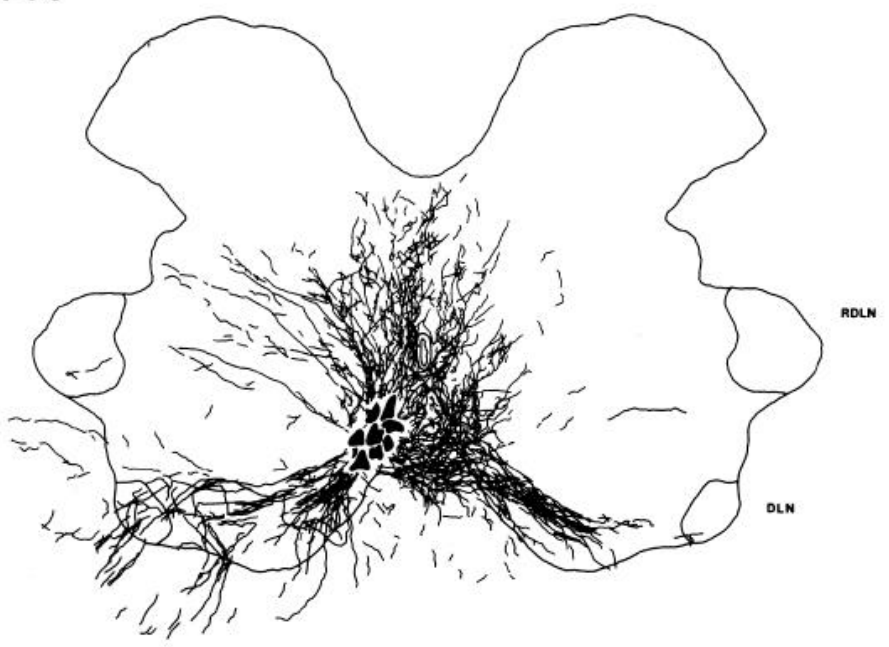

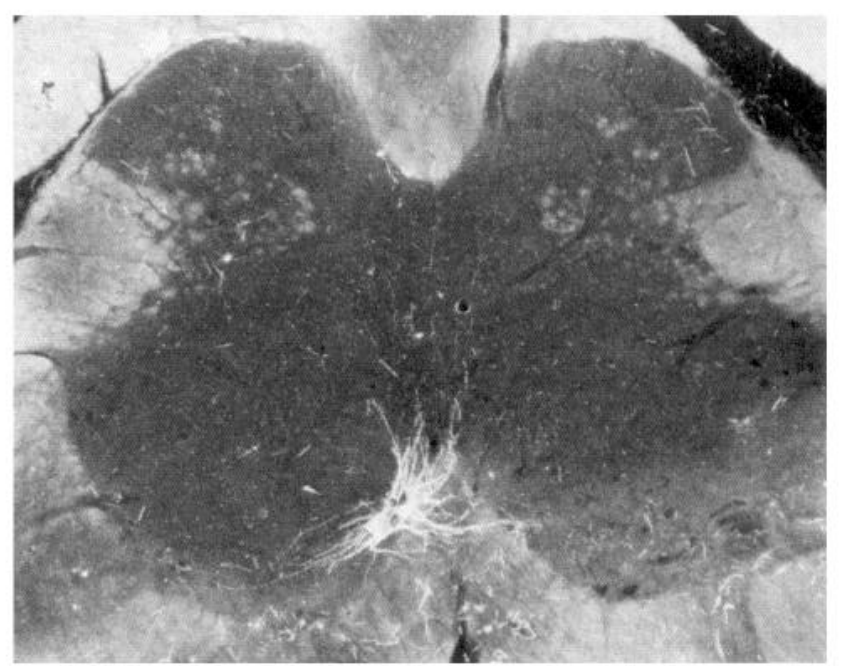

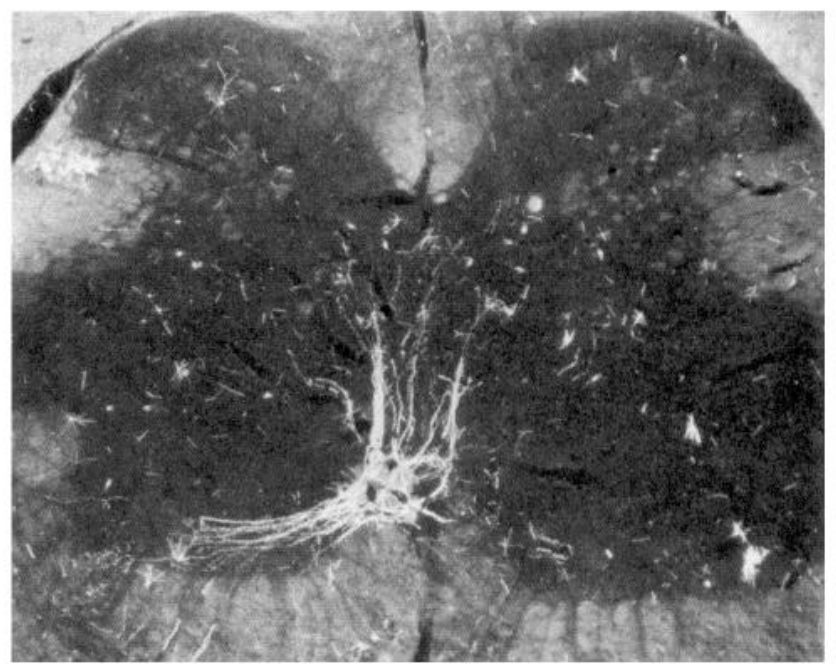

Figure 7. Left, Camera lucida composite drawings of CTHRP-labeled processes drawn at $320 \mu \mathrm{m}$ intervals through the total extent of the SNB. Right, Dark-field photomicrographs of transverse sections through the lumbar spinal cord of a male castrated at P28 and implanted with a blank implant (upper) or an implant containing testosterone (lower) after CTHRP injection into the BC muscle at P70. Abbreviations and scale as in Figure 1.

occurs primarily at the tips of the terminal branches (Petit et al., 1988). Finally, neurons in the superior cervical ganglia (SCG) show a prolonged growth phase lasting through 30 weeks of age, with the dendritic arbor progressively becoming more extensive and complex (Voyvodic, 1987). In this case, dendritic length and maximum extent are both linearly related to body weight. However, SCG dendritic growth is not considered to be the result of simple elongation, but more likely represents continual expansion and retraction of individual branches with expansion presumably dominating over retraction (Purves et al., 1986; Voyvodic, 1987). It seems possible that this dual mechanism operates even in systems which exhibit a biphasic pattern of dendritic development, with expansion dominating in the initial growth phase and the elimination of branches dominating during the subsequent retractive phase.

\section{Factors controlling dendritic development}

Various factors have been hypothesized to regulate dendritic development, including properties intrinsic to the neuron, afferent input, and trophic substances. Our results indicate that androgens are also a critical factor for dendritic development of the steroid-sensitive SNB motoneurons, either by acting directly or by regulating other factors. Such an involvement of steroid hormones on dendritic or synaptic development has previously been indicated in other sexually dimorphic brain regions, such as the hypothalamus (Raisman and Field, 1973; Matsumoto and Arai, 1981; Toran-Allerand et al., 1983).

The initial outgrowth of dendrites and the number and orientation of primary processes appear to be intrinsically determined by factors inherent to developing neurons. For example, 
although the mutant reeler and weaver mice have profoundly altered cerebellar structure and connectivity, the rate of initial dendritic outgrowth and spine formation in Purkinje cells remains normal. However, the development of higher-order dendrites is stunted, and their distribution is random (Rakic, 1975; Berry et al., 1978). Even before significant synaptic input to retinal ganglion cells is established, the size and pattern of dendritic arbors of specific cell types is present, suggesting that these are intrinsically determined (Maslim et al., 1986). Finally, characteristic features of dendritic morphology are expressed by neurons growing in culture, permitting easy identification of cell types (Banker and Cowan, 1979; Banker and Waxman, 1988). This apparent immutability of certain features of neuronal form is also seen in SNB motoneurons. For example, the number of primary processes and the overall distribution of dendritic arbor of SNB motoneurons may be determined intrinsically. These features are present regardless of the target muscle innervated (BC vs LA) or after prenatal hormonal manipulation (e.g., dihydrotestosterone treatment; see Kurz et al., 1989a). In the present study, the dendritic topology of SNB motoneurons at even the earliest age examined was similar to that seen at all other ages. Furthermore, this topology was not altered by castration or hormone treatment and thus may reflect an intrinsic property.

While certain aspects of dendritic development, such as growth rate, may be genetically controlled, the pattern and degree of higher-order branching depend upon the contacts made with incoming afferents (Morest, 1969a; Berry et al., 1978; Berry, 1982; Vaughn et al., 1988). The onset of function in afferents may influence dendritic growth and branching patterns more than simply the physical presence of these afferents. In nucleus laminaris in chick, the development of dendritic length gradients is contemporaneous with the onset of function rather than with synaptogenesis (Smith, 1981). In nonpyramidal auditory cortical neurons of rabbits, alterations in afferent activity produced by ulilateral neonatal deafening change dendritic length and orientation (McMullen et al., 1988). However, Voyvodic (1987) observed no immediate effect of deafferentation on dendritic growth of SCG neurons in rats.

Afferents to SNB motoneurons may be important in regulating dendritic growth and retraction during development. Following unilateral destruction of the nucleus by neonatal target ablation, dendritic length in the remaining SNB is over $50 \%$ longer than normal (Kurz et al., 1989b). This increased length may result from a retention of the early exuberant arbor we observed at P28. Because the dendritic arbors of the nuclei overlap extensively at all ages, unilateral destruction of the SNB might reduce competition between dendrites for incoming afferents, permitting the retention of the early exuberant length. Possible afferents to the SNB include reticular nuclei in the pons and medulla, raphe nuclei, vestibular nuclei, and several sites in the hypothalamus (Monaghan and Breedlove, 1986; Shen et al., 1989). Androgens might interact with these afferents and/ or postsynaptically to regulate this competition and concomitant dendritic remodeling.

Another potential influence on dendritic development may be the interaction of SNB motoneurons and their target musculature. At P14, about $90 \%$ of LA muscle fibers are multiply innervated. Synapse elimination, through which the adult pattern of single innervation of muscle fibers is achieved, occurs primarily between P14 and P28 (Jordan et al., 1988). This process is regulated by androgens; castration at P7 hastens the elimination of multiple innervation in the LA, whereas castra- tion followed by androgen replacement results in the retention of multiple inputs to LA muscle fibers (Jordan et al., 1989a, b; Lubischer et al., 1989). Similarly, SNB dendritic development is exuberant at $\mathrm{P} 28$, and subsequently retracts to adult lengths by $\mathrm{P} 49$. This retraction is also regulated by androgens, and the early exuberant length can be retained with androgen treatment. It is possible that androgens may be acting on some factor common to both processes - perhaps by modulating neural activity (Thompson et al., 1979; Smith, 1981) or the supply of potential trophic factors (Purves, 1986).

In general, dendrites of spinal motoneurons develop after target muscle innervation (Ramón y Cajal, 1909-1911). This pattern of peripheral-to-central development is present in the SNB as well, in that the development of neuromuscular connectivity (primarily P14 through P28; Jordan et al., 1988) precedes the establishment of mature dendritic morphology (P28P49). Given that the majority of synapse elimination in the LA muscle has been completed prior to the retraction of SNB dendrites, it is possible that the establishment of mature peripheral connectivity may direct or perhaps be a prerequisite for the establishment of mature dendritic architecture of SNB motoneurons.

\section{Androgen effects on dendritic growth}

Animals castrated at P7 and treated with oil showed no changes in dendritic length from P7 values at either P28 or P49 (see Figs. 4,5 ), indicating that the presence of gonadal $T$ during the first 4 weeks of postnatal development is necessary for normal dendritic growth. Conversely, animals castrated at P7 and injected with TP had dendritic lengths at P28 that were identical to those of normal males at the same age. Interestingly, dendritic lengths of the TP-treated and normal males were the same even though the TP-treated males received a dosage of TP between P7 and P28 calculated to result in plasma concentrations far in excess of what would normally be present at these ages (Resko et al., 1968; Damassa et al., 1977; Moger, 1977; Ketelslegers et al., 1978; Corpechot et al., 1981; Jordan et al., 1989a). The observation that dendritic development was not enhanced beyond normal P28 levels by exogenous TP treatment suggests that the developing SNB motoneurons may be at a metabolic limit for dendritic growth. While androgens are required for this growth, increasing $\mathrm{T}$ concentrations above the concentration normally present through the early postnatal period would thus have no effect. This hypothetical limit may apply in adult males as well-while androgen replacement following castration restores SNB dendritic length (Kurz et al., 1986a), elevations in $T$ titers above normal basal levels do not produce further increases above normal lengths (Beversdorf et al., 1989).

\section{Androgen effects on dendritic retraction}

Why does SNB dendritic length begin to decline to adult levels after P28? If initial dendritic growth can be supported by even the low $T$ levels reported to be present during the first postnatal weeks, this retraction seems paradoxical, especially given that $\mathrm{T}$ levels are reported to increase after P28 with the onset of puberty (Resko et al., 1968; Moger, 1977; Ketelslegers et al., 1978; Corpechot et al., 1981). One possible explanation may be that the androgen requirements of SNB motoneurons also increase at this time, making the low level of $T$ present insufficient to support further dendritic growth or even stabilize the arbor at P28 lengths, and dendritic retraction results.

While SNB motoneurons in adult males have androgen re- 
ceptors and heavily accumulate androgens (Breedlove and Arnold, 1980, 1983c), androgen accumulation by SNB motoneurons cannot be demonstrated by autoradiographic techniques in early postnatal animals (Breedlove, 1986). An increase in the concentration of androgen receptors has been reported in the hypothalamus-preoptic area of rats and mice during the first few weeks of birth (Vito and Fox, 1982), and a similar increase has been hypothesized for testicular cells between P25 and P45 (Buzek and Sanborn, 1988). These increases in androgen receptors are consistent with an increasing influence of or dependence on androgens in these tissues, and this type of change in SNB motoneurons might underlie the dendritic retraction. Thus, the cessation of retraction by $\mathrm{P} 49$ may reflect an attainment of a critical concentration of plasma $T$ which stabilizes the SNB dendritic arbor.

Androgen-treated castrates at P49 had dendritic arbors which were atypically large for this age, and were remarkably similar to the exuberant lengths seen normally at P28 (see Fig. 6). This hypertrophy in length at P49 further supports the hypothesis that the normal increase in androgen levels to a critical concentration may halt SNB dendritic retraction. Because our androgen dosages were calculated to produce much higher $\mathrm{T}$ titers than would be present in males between P28 and P49, their high $\mathrm{T}$ concentrations may have prematurely halted the normal retraction process. Alternatively, dendritic growth and retraction may involve separate cellular processes which can occur simultaneously, and the alternating dominance of one process over the other normally produces a biphasic pattern of development (see above). Thus, it is possible that the exuberant dendritic length of T-implanted castrates at P49 was due to an androgen-enhanced dendritic growth superimposed on a normal retraction, rather than reflecting a retention of early exuberance through an inhibition of this retraction. Regardless of the mechanism or mechanisms involved, this hypermasculine dendritic length at P49 is temporary, and dendritic length in T-implanted castrates was no longer different from that of normal males at P70.

If the increase in $\mathrm{T}$ titers reported to occur with the onset of puberty does halt the retraction of SNB dendrites, it might be predicted that the amount of retraction seen at P49 should be enhanced after castration. However, the extent of dendritic retraction in blank-implanted castrates was not different from that of normal males at $\mathrm{P} 49$. It is possible that the rate of retraction is set by metabolic or physiological maxima for SNB motoneurons at this age and cannot be hastened by hormonal manipulation. Alternatively, if normal SNB dendritic retraction is a result of insufficient androgen concentration as hypothesized above, having a subcritical androgen concentration as the result of either castration or juvenile $\mathrm{T}$ titers could still result in an equivalent retraction through $\mathrm{P} 49$. However, by $\mathrm{P} 70$, SNB motoneurons of blank-implanted castrates have shorter dendritic lengths than do normal animals, suggesting that the lack of gonadal testosterone may eventually result in an enhanced retraction. It may also be the case that this reduced dendritic length at P70 simply reflects the typical SNB dendritic response to castration reported in adult males (Kurz et al., 1986a; Forger and Breedlove, 1987).

\section{Development of soma size}

The present results indicate that SNB motoneuron soma size can develop in a normal masculine fashion in the absence of androgens from P7 through P49 (see Figs. 2, 3). These results are consistent with those of Lee et al. (1989), who investigated the duration of the critical period for the masculinization of soma size in female rats exposeci to androgens during various postnatal periods. Their data reveal that SNB motoneuron soma area in females can be masculinized by exposure to androgens through P11, without further exposure until adulthood. However, androgen treatment beginning after this period did not significantly increase soma size over that of normal females. They conclude that the masculinization of SNB soma size requires exposure to androgens during a critical period that includes the first 2 postnatal weeks. Our results support this conclusion by demonstrating that males exposed to endogenous androgens until P7, and then castrated, have masculine SNB soma sizes at least until P49. At P70, castrates without androgens have significantly smaller SNB somas than those of normal males, suggesting that (in terms of soma size), the adult response to androgen removal is present by this age (Kurz et al., 1986a; see Fig. 3).

The effect of androgen treatment on soma size in Experiments II and III indicates that while the development of masculine SNB soma size does not require androgens after $\mathrm{P} 7$, the timing of somal development can be altered by androgens. When castrates are given high dosages of androgens at early ages (starting at either P7 or P28; see Figs. 2, 3), SNB soma size reaches its adult range sooner than somas in normal males, which are reported not to reach adult levels of androgens until after P49 (Resko et al., 1968; Moger, 1977; Ketelslegers et al., 1978; Corpechot et al., 1981). This hypothesis may account for the difference in soma size between androgen-treated and normal animals at P28 in Experiment II, and at P49 in both Experiments II and III. By P70, however, SNB motoneuron somas in normal males have also reached adult sizes and are not different from those of androgen-treated animals. Again, it appears that the adult pattern of response to changing androgen levels is present by $\mathrm{P} 70$.

Sexual differentiation of the SNB neuromuscular system involves the regulation of a variety of formative processes by androgens, including neuronal death, somal growth, the elimination of multiple inputs to target muscles, and the specification of peripheral projections (Breedlove, 1985; Nordeen et al., 1985; Kurz et al., 1986b, 1987; Jordan et al., 1988, 1989a, b; Lee et al., 1989). The present studies demonstrate that androgens also play a critical role in the development of SNB dendritic arbor. Androgens are necessary for the initial period of exuberant growth, and pubertal changes in androgen titers may regulate dendritic retraction to stabilize the arbor at mature lengths. Together, these fundamental processes and their regulation by steroid hormones may underlie the development of sexual dimorphisms throughout the nervous system, producing differences in neuron number, size, and connectivity.

\section{References}

Arnold, A. P., and R. A. Gorski (1984) Gonadal steroid induction of structural sex differences in the central nervous system. Annu. Rev. Neurosci. 7: 413-442.

Arnold, A. P., S. W. Bottjer, E. J. Nordeen, K. W. Nordeen, and D. R. Sengelaub (1987) Hormones and critical periods in behavioral and neural development. In Imprinting and Cortical Plasticity. J. P. Raushecker and P. Marler, eds., pp. 55-97, Wiley, New York.

Banker, G. A., and W. M. Cowan (1979) Further observations on hippocampal neurons in dispersed cell culture. J. Comp. Neurol. 187 : $469-494$.

Banker, G. A., and A. B. Waxman (1988) Hippocampal neurons generate natural shapes in cell culture. In Intrinsic Determinants of Neu- 
ronal Form and Function. Neurology and Neurobiology, Vol. 37, R. J. Lasek and M. M. Black, eds., pp. 61-82, Liss, New York.

Berry, M. (1982) Cellular differentiation: Development of dendritic arborizations under normal and experimentally altered conditions. In Development and Modifiability of the Cerebral Cortex, P. Kakic and P. S. Goldman-Rakic, eds., pp. 451-461, MIT Press, Cambridge, MA. Berry, M., P. Bradley, and S. Borges (1978) Environmental and genetic determinants of connectivity in the central nervous system-An approach through dendritic field analysis. Prog. Brain Res. 48: 133148.

Beversdorf, D. Q., E. M. Kurz, and D. R. Sengelaub (1989) Sexual activity and the morphology of steroid-sensitive rat spinal motoneurons. Physiol. Behav. (in press).

Breedlove, S. M. (1985) Hormonal control of the anatomical specificity of motoneuron-to-muscle innervation in rats. Science 227: 13571359.

Breedlove, S. M. (1986) Absence of androgen accumulation by motoneurons of neonatal rats. Soc. Neurosci. Abstr. 12: 1220.

Breedlove, S. M., and A. P. Arnold (1980) Hormone accumulation in a sexually dimorphic motor nucleus of the rat spinal cord. Science 210: 564-566

Breedlove, S. M., and A. P. Arnold (1981) Sexually dimorphic motor nucleus in rat spinal cord: Response to adult hormone manipulation, absence in androgen-insensitive rats. Brain Res. 225: 297-307.

Breedlove, S. M., and A. P. Arnold (1983a) Hormonal control of a developing neuromuscular system: I. Complete demasculinization of the male rat spinal nucleus of the bulbocavernosus using the antiandrogen flutamide. J. Neurosci. 3: 417-423.

Breedlove, S. M., and A. P. Arnold (1983b) Hormonal control of a developing neuromuscular system: II. Sensitive periods for the androgen-induced masculinization of the rat spinal nucleus of the bulbocavernosus. J. Neurosci. 3: 424-432.

Breedlove, S. M., and A. P. Arnold (1983c) Sex differences in the pattern of steroid accumulation by motoneurons of the rat lumbar spinal cord. J. Comp. Neurol. 215: 211-216.

Breedlove, S. M., C. D. Jacobson, R. A. Gorski, and A. P. Arnold (1982) Masculinization of the female rat spinal cord following a single neonatal injection of testosterone propionate but not estradiol benzoate. Brain Res. 237: 173-181.

Buzek, S. W., and B. M. Sanborn (1988) Increase in testicular androgen receptor during sexual maturation in the rat. Biol. Reprod. 39: 3949.

Cihak, R., E. Gutmann, and V. Hanzlikova (1970) Involution and hormone-induced persistence of the muscle sphincter (levator) ani in female rats. J. Anat. (Lond.) 106: 93-110.

Corpechot, C., E. E. Baulieu, and P. Robel (1981) Testosterone, dihydrotestosterone, and androstanediols in plasma, testes, and prostates of rats during development. Acta Endocrinol. 96: 127-135.

Damassa, D. A., E. R. Smith, B. Tennent, and J. M. Davidson (1977) The relationship between circulating testosterone levels and male sexual behavior in rats. Horm. Behav. 8: 275-286.

Dann, J. F., E. H. Buhl, and L. Peichl (1988) Postnatal dendritic maturation of alpha and beta ganglion cells in cat retina. J. Neurosci. 8: 1485-1499.

Dube, J. Y., R. Lesage, and R. R. Tremblay (1976) Androgen and estrogen binding in rat skeletal and perineal muscles. Can. J. Biochem. 54: $50-55$.

Falls, W., and S. Gobel (1979) Golgi and EM studies of the formation of dendritic and axonal arbors: The interneurons of the substantia gelatinosa of Rolando in newborn kittens. J. Comp. Neurol. 187: 118 .

Forger, N. G., and S. M. Breedlove (1987) Seasonal variation in striated muscle mass and motoneuron morphology. J. Neurobiol. 18:155165.

Goldstein, L. A., and D. R. Sengelaub (1989) Androgen metabolites masculinize motoneuron number in a sexually dimorphic rat spinal nucleus. Soc. Neurosci. Abstr. 15:87.

Goy, R. W., and B. S. McEwen (1980) Sexual Differentiation of the Brain, MIT Press, Cambridge, MA.

Greenough, W. T., and F.-L. F. Chang (1988) Dendritic pattern formation involves both oriented regression and oriented growth in the barrels of mouse somatosensory cortcx. Dev. Brain Res. 43: 148152.

Hart, B. L., and P. Y. Melese-D'Hospital (1983) Penile mechanisms and the role of the striated penile muscles in penile reflexes. Physiol. Behav. 31: 802-813.
Jordan, C. L., M. S. Letinsky, and A. P. Arnold (1988) Synapse elimination occurs late in the hormone-sensitive levator ani muscle of the rat. J. Neurobiol. 19: 335-356.

Jordan, C. L., M. S. Letinsky, and A. P. Arnold (1989a) The role of gonadal hormones in neuromuscular synapse elimination in rats. I. Androgen delays the loss of multiple innervation in the levator ani muscle. J. Neurosci. 9: 229-238.

Jordan, C. L., M. S. Letinsky, and A. P. Arnold (1989b) The role of gonadal hormones in neuromuscular synapse elimination in rats. II. Multiple innervation persists in the adult levator ani muscle after juvenile androgen treatment. J. Neurosci. 9: 239-247.

Kelley, D. B. (1986) The genesis of male and female brains. TINS 9 499-502.

Ketelslegers, J.-M., W. D. Hetzel, R J. Sherins, and K. J. Catt (1978) Developmental changes in testicular gonadotropin receptors: Plasma gonadotropins and plasma testosterone in the rat. Endocrinology 103: 212-222.

Kurz, E. M., D. R. Sengelaub, and A. P. Arnold (1986a) Androgens regulate the dendritic length of mammalian motoneurons in adulthood. Science 232: 395-398.

Kurz, E. M., D. R. Sengelaub, and A. P. Arnold (1986b) Morphology of rat spinal motoneurons with normal and hormonally altered specificity. Soc. Neurosci. Abstr. 12: 1218.

Kurz, E. M., C. A. Bowers, and D. R. Sengelaub (1987) Selective androgen effects on rat spinal motoneuron morphology and connectivity. Soc. Neurosci. Abstr. 13: 1518 .

Kurz, E. M., C. A. Bowers, and D. R. Sengelaub (1989a) Morphology of rat spinal motoneurons with normal and hormonally altered specificity. J. Comp. Neurol. (in press).

Kurz, E. M., L. A. Goldstein, and D. R. Sengelaub (1989b) Evidence for dendritic competition in the development of motoneuron morphology in the rat spinal cord. Soc. Neurosci. Abstr. 15: 67.

Lasiter, P. S., D. M. Wong, and D. L. Kachele (1989) Postnatal development of the rostral solitary nucleus in rat: Dendritic morphology and mitochondrial enzyme activity. Brain Res. Bull. 22:313-321.

Lee, J. H., C. L. Jordan, and A. P. Arnold (1989) Critical period for androgenic regulation of soma size of sexually dimorphic motoneurons in rat spinal cord. Neurosci. Lett. 98: 79-84.

Lubischer, J. L., C. L. Jordan, and A. P. Arnold (1989) Juvenile androgen treatment permanently prevents synapse elimination in the levator ani muscle. Soc. Neurosci. Abstr. 15: 127.

MacLusky, N. J., and F. Naftolin (1981) Sexual differentiation of the central nervous system. Science 211: 1294-1303.

Maslim, J., M. Webster, and J. Stone (1986) Stages in the structural differentiation of retinal ganglion cells. J. Comp. Neurol. 254: $382-$ 402.

Matsumoto, A., and Y. Arai (1981) Effect of androgen on sexual differentiation of synaptic organization in hypothalamic arcuate nucleus: An ontogenetic study. Neuroendocrinology 33: 166-169.

Matsumoto, A., P. E. Micevych, and A. P. Arnold (1988a) Androgen regulates synaptic input to motoneurons of the adult rat spinal cord J. Neurosci. 8: 4168-4176.

Matsumoto, A., A. P. Arnold, G. A. Zampighi, and P. E. Micevych (1988b) Androgenic regulation of gap junctions between motoneurons in the rat spinal cord. J. Neurosci. 8: 4177-4183.

McKenna, K. E., and I. Nadelhaft (1986) The organization of the pudendal nerve in the male and female rat. J. Comp. Neurol. 248. 532-549.

McMullen, N. T., B. Goldberger, C. M. Suter, and E. M. Glaser (1988) Neonatal deafening alters nonpyramidal dendrite orientation in auditory cortex: A computer microscope study in the rabbit. J. Comp. Neurol. 267: 92-106.

Mcancy, M. J., and J. Stcwart (1981) A descriptive study of social development in the rat (Rattus norvegicus). Anim. Behav. 29: 34-45.

Mesulam, M. M. (1978) Tetramethyl benzidine for horseradish peroxidase neurohistochemistry: A noncarcinogenic blue reaction-product with superior sensitivity for visualizing neural afferents and efferents. J. Histochem. Cytochem. 27: 106-117.

Moger, W. H. (1977) Serum 5a-androstane-3a,17B-diol, androsterone, and testosterone concentrations in the male rat. Influence of age and gonadotropin stimulation. Endocrinology 100: 1027-1032.

Monaghan, E. P., and S. M. Breedlove (1986) Possible brain sites innervating spinal nucleus of the bulbocavernosus. Soc. Neurosci. Abstr. 12: 1219.

Morest, D. K. (1969a) The differentiation of cerebral dendrites: A 
study of the postmigratory neuroblast in the medial nucleus of the trapezoid body. Z. Anat. Entwickl.-Gesch. 128: 271-289.

Morest, D. K. (1969b) The growth of dendrites in the mammalian brain. Z. Anat. Entwickl.-Gesch. 128: 290-317.

Nordeen, E. J., K. W. Nordeen, D. R. Sengelaub, and A. P. Amold (1985) Androgens prevent normally occurring cell death in a sexually dimorphic spinal nucleus. Science 229: 671-673.

Petit, T. L., J. C. LeBoutillier, A. Gregorio, and H. Libstug (1988) The pattern of dendritic development in the cerebral cortex of the rat. Dev. Brain Res. 41: 209-219.

Purves, D. (1986) The trophic theory of neural connections. TINS 9: $486-498$.

Purves, D., R. D. Hadley, and J. T. Voyvodic (1986) Dynamic changes in the geometry of individual neurons visualized over periods of up to three months in the superior cervical ganglion of living mice. J. Neurosci. 6: 1051-1060.

Raisman, G., and P. M. Field (1973) Sexual dimorphism in the neuropil of the preoptic area of the rat and its dependence on neonatal androgen. Brain Res. 54: 1-29.

Rakic, P. (1975) Role of cell interaction in development of dendritic patterns. Adv. Neurol. 12: 117-134.

Ramoa, A. S., G. Campbell, and C. J. Shatz (1987) Transient morphological features of identified ganglion cells in living fetal and neonatal retina. Science 237: 522-525.

Ramon y Cajal, S. (1909-1911) Histologie du Systéme Nerveux de l'Homme et des Vertèbres, L. Ayoulay, trans., pp. 1952-1955, Madrid.

Resko, J. A., H. H. Feder, and R. W. Goy (1968) Androgen concentrations in plasma and testis of developing rat. J. Endocrinol. 40:485491.

Sachs, B. D. (1982) Role of the rat's striated penile muscles in penile reflexes, copulation, and the induction of pregnancy. J. Reprod. Fertil. 66: $433-443$.

Sachs, B. D., and Meisel, R. L. (1979) Pubertal development of penile reflexes and copulation in male rats. Psychoneuroendocrinology 4: 287-296.

Schroder, H. D. (1980) Organization of the motoneurons innervating the pelvic muscles of the male rat. J. Comp. Neurol. 192: 567-587.

Sengelaub, D. R., and A. P. Arnold (1986) Development and loss of early projections in a sexually dimorphic rat spinal nucleus. J. Neurosci. 6: 1613-1620.

Sengelaub, D. R., C. L. Jordan, E. M. Kurz, and A. P. Arnold (1989a) Hormonal control of neuron number in sexually dimorphic spinal nuclei of the rat: II. Development of the spinal nucleus of the bul- bocavernosus in androgen-insensitive ( $\mathrm{Tfm}$ ) rats. J. Comp. Neurol. $280 \cdot 630-636$

Sengelaub, D. R., E. J. Nordeen, K. W. Nordeen, and A. P. Arnold (1989b) Hormonal control of neuron number in sexually dimorphic spinal nuclei of the rat: III. Differential effects of the androgen dihydrotestosterone. J. Comp. Neurol. 280: 637-644.

Shen, P., A. P. Arnold, and P. E. Micevych (1989) Possible afferent projections to the spinal nucleus of the bulbocavernosus in adult male rats. Soc. Neurosci. Abstr. 15: 578.

Smith, Z. D. J. (1981) Organization and development of brain stem auditory nuclei of the chicken: Dendritic development in $N$. laminaris. J. Comp. Neurol. 203: 309-333.

Smith, E. R., D. A. Damassa, and J. M. Davidson (1978) Hormone administration: Peripheral and intracranial implants. In Methods in Psychobiology, Vol. 3, R. D. Meyer, ed., pp. 259-279, Academic Press, New York.

Sodersten, P., D. A. Damassa, and E. R. Smith (1977) Sexual behavior in developing male rats. Horm. Behav. 8: 320-341.

Thompson, W., D. P. Kuffler, and J. K. S. Jansen (1979) The effect of prolonged, reversible block of nerve impulses on the elimination of polyneuronal innervation of new-born rat skeletal muscle fibers. Neuroscience 2: 271-281.

Toran-Allerand, C. D., K. Hashimoto, W. T. Greenough, and M. Saltarelli (1983) Sex steroids and the development of the newborn mouse hypothalamus and preoptic area in vitro: III. Effects of estrogen on dendritic differentiation. Dev. Brain Res. 7: 97-101.

Ueyama, T., H. Arakawa, and N. Mizuno (1987) Central distribution of efferent and afferent components of the pudendal nerve in rat. Anat. Embryol. (Berl.) 177: 37-49.

Vaughn, J. E., R. P. Barber, and T. J. Sims (1988) Dendritic development and preferential growth into synaptogenic fields: A quantitative study of Golgi-impregnated spinal motor neurons. Synapse 2 . 69-78.

Vito, C. C., and T. O. Fox (1982) Androgen and estrogen receptors in embryonic and neonatal rat brain. Dev. Brain Res. 2: 97-110.

Voyvodic, J. T. (1987) Development and regulation of dendrites in the rat superior cervical ganglion. J. Neurosci. 7: 904-912.

Wainman, P., and G. C. Shipounoff (1941) The effects of castration and testosterone propionate on the striated perineal musculature of the rat. Endocrinology 29: 955-978.

Weiss, G. M., and J. J. Pysh (1978) Evidence for loss of Purkinje cell dendrites during late development: A morphometric Golgi analysis in the mouse. Brain Res. 154: 219-230. 